\title{
Ecological and Socio-Economic Stress of Invasive Alien Species Synergic with Climate Change. A Worldwide Review
}

\author{
Mastewal Hailemariam \\ Department of Biology, College of Natural and Computational Science, Debre Berhan University, Ethiopia
}

\begin{abstract}
Invasive alien species are non-indigenous species that adversely affect, economically, environmentally or ecologically habitats. Invasive alien species (IAS) and climate change are identified as the top drivers of global biodiversity loss. Synergistically, climate change and IAS will greatly threatening biodiversity, ecology, economy, food security and other human welfare. Furthermore, both climate change and IAS can affect production landscapes, reducing crop yields and the provision of ecosystem services. Climate change can facilitate IAS as: new species, that may become invasive, will be entering regions due to climate change; species hierarchies in ecosystems will change leading to new dominants that may have invasive tendencies; and climate induced stress in an ecosystem will facilitate invasive pathways. Alternatively, IAS can facilitate climatic stress by increasing ecosystem susceptibility to climatic perturbation, through reducing the number of species and their functional types within the ecosystem. IAS should be recognized as a component of climate change and as such appropriate research strategies, funding mechanisms, policy development and implementation need to be developed in the world.
\end{abstract}

Keywords: Climate Change, Ecology, Impact, Invasive

DOI: $10.7176 / \mathrm{JRDM} / 54-03$

Publication date: April $30^{\text {th }} 2019$

\section{INTRODUCTION}

Invasive species and climate change are widely recognized as pressing environmental and socio-economic issues worldwide (Smith et al., 2012). Biological invasion has become one of the major causes of economic and environmental damage across the world and its impacts have been predicted to increase even further under future climatic conditions (Thapa et al., 2018; Shiferaw et al., 2018). The Convention on Biological Diversity (1992) emphasized biological invasion as one of the major driver of biodiversity decline and the second biggest threat after habitat destruction and ecosystem degradation (Preisser et al., 2008). Impacts of biological invasions are often difficult to measure but they have been shown to be pervasive from the population to the community and ecosystem levels (Simberloff et al., 2013).

Majority of the species are alien (Senayit et al., 2004) in the sense that they are non-native organisms that cause, or have the potential to cause harm to the environment, economies, or human health (Shiferaw et al., 2018). Invasive alien species (IAS) are any taxa that are moved beyond their previous range by human agency, either deliberately or accidentally, and that cause environmental and socio-economic harm in their new surroundings (McNeely, 2001). Once introduced into an ecosystem, the species have the ability to establish themselves with immense potential to invade and out-compete native varieties and eventually take over the new environment (Senayit et al., 2004).

IAS are increasing in number, extent, and influence worldwide (Pyšek and Richardson, 2010). Climate Change, anthropogenic pressure, and land use change have accelerated bio-invasion (Thapa et al., 2018). Changes in climate are not new phenomena in the history of the Earth (Paillard, 2001). It have a synergistic impact with biological invasions in many ways. Climate change can be continuing to create new and suitable habitat for invasive species establishment, and therefore enhancing the invasion process (Bradley et al., 2009; Bellard et al., 2016). Climate change and IAS could increasingly interact in a positive feedback loop, with climate change opening up new habitat for IAS, and IAS subsequently (CABI, 2009). Therefore, the negative impacts of IAS will be aggravated by climate change (Bellard et al., 2013; Seebens et al., 2015). Climate change, and societal responses to it, are likely to intensify the impacts of IAS at all stages of the invasion process, by providing increased opportunities for IAS to cross historical geographic barriers, and to establish and spread in new areas (Walther et al., 2009). At the same time, IAS may influence the magnitude, rate, and impact of climate change by altering ecosystem structure and function (Pyke et al., 2008). IAS will also respond to climate change, and their responses will have ecological and economic implications (Hellmann et al., 2008).

Invasive alien species are one of the most significant drivers of environmental change worldwide, consequently placing constraints on environmental conservation, economic growth, and sustainable development. IAS may also contribute to social instability and economic hardship (Shiferaw et al., 2018). A general estimate of economic losses and ecological damages caused by invasive species is measured in tens of billions of dollars per year (Pimentel et al., 2005) and the potential economic loss to global agriculture alone is worth several billions of dollar annually (Paini et al., 2016). While the ecological impacts of invasive species 
have been generally well-studied, the many ways in which such species impact ecosystem services and human well-being are still emerging (Pejchar and Mooney, 2009).

Many IAS are pathogens, pests or weeds, costing the global economy of the order of many hundreds of billions of dollars each year (Vié, et al., 2009). These species advance also into rangelands bringing about shortages in forages and animal feed. Invasion of agricultural lands also has effects on crop outputs with an overall impact on the economy of the country and food security (Sintayehu, 2007). They can also include unemployment, impacts on infrastructure, food and water shortages, environmental degradation, loss of biodiversity, increased rates and severity of natural disasters, illness, and lost lives (CABI, 2009). It is estimated that $25 \%$ of all mammal species, $13 \%$ of all bird species, and over 21000 species of plants face a high probability of extinction within a 50-year window (Tilman et al., 2017).

Synergistic combinations are likely to lead to significantly increased vulnerability with climate change. Elevated $\mathrm{CO} 2$, increased temperature, changed precipitation patterns and an increased frequency of extreme events such as fire frequency and flooding will all have significant impacts on ecosystems and IAS (CABI, 2009). Moreover, IAS together with climate change are one of the leading and most rapidly growing threats to food security, human and animal health, and biodiversity and, one of the most difficult to reverse (Pimentel et al., 2001). Therefore, climate change and IAS are considered to be primary threats to poverty alleviation, biodiversity and ecosystem functioning globally (Steffen et al., 2015; Tilman et al., 2017).

Therefore, in developing management strategies for invasive species, there needs to be a consideration of the climate change factors that can affect their distribution. Including climate change in management of invasive species helps to minimize the threat of these species in the future (Crossman et al., 2011). Furthermore, understanding the factors that affect the spread of invasive species and identifying their potential distribution and impacts are essential for controlling their further spread (With, 2002). Awareness of the dangers posed by IAS is far less well publicized and would seem to be an environmental problem several orders of magnitude smaller than that posed by climate change. A point that really needs to be appreciated the problem of IAS and climate change are inextricably linked. However, the synergy between IAS and climate change is complex and poorly understood (CABI, 2009). In points of these, this review paper explore and examine different facets of how alien invasive species and climate change interactively affect ecological, social and economic aspects in the world.

\section{Concepts of Invasive Alien Species}

There are several definitions for invasive and alien species. Alien species is a species when it is intentionally or unintentionally introduced in a location, area, or region where it does not occur naturally Sintayehu, 2007. Common usage of terms include non-indigenous, non-native, exotic, foreign, new, pest etc. (Shine, 2000). According to the Convention on Biological Diversity (CBD), Alien Species are referred to as "species, subspecies or lower taxon, introduced outside its natural past or present distribution, including any part, gametes, seeds, eggs, or, propagules of such species that might survive and subsequently reproduce" (CBD, 1992 cited in Sintayehu, 2007).

However, the term "Invasive" likewise has no generally accepted meaning. The basic element imbedded in invasiveness is however linked to the adverse impact that the species imposes on the receiving environmental media (Shine, 2000). Invasiveness includes alien species that escape from human control, go beyond the intended physical boundaries and clause environmental damage (Shine, 2000). In comparison to native species, the invasive species are usually more abundant, tolerant to a broad range of climatic condition, and possess highly competitive biological traits hence they are more likely to adapt to new climate conditions (Hellmann et al., 2008).

Invasive alien species (IAS) is an alien species that has established and spread, and which causes, or has the potential to cause, harm to the environment, economies, or human health. There are various versions of the IAS definition. For example, the Convention on Biological Diversity (CBD) defines an IAS as an alien species whose establishment and spread threatens ecosystems, habitats or species with economic or environmental harm (Sundaram et al., 2018).

According to the IUCN an IAS is an alien species which becomes established in natural or semi-natural ecosystems or habitats, is an agent of change, and threatens native biological diversity. An alien species is considered invasive only if it has adverse impacts on the environment, the economy or human health. Invasive alien species is an alien species which threatens ecosystems, habitats or species. (1) Alien species that escape from human control go beyond the intended physical boundaries and cause environmental damage, (2) Covers alien species that remain under human control but damage native ecosystems. Such damage is linked to species being alien, but not to invasiveness (Shiferaw et al., 2018). Moreover, lAS are non-native flora or faunal species that easily establish and spread outside their natural distribution range (Zelalem, 2007).

\section{Characteristics of Invasive Alien Species}

Invasive species typically are successful and abundant, whereas many native species are rare. Many invasive 
species also have characteristics that differ from non-invasive species. For example, many invasive plants have broad climatic tolerances and large geographic ranges (Qian and Ricklefs, 2006; Hellmann et al., 2008), and these characteristics may affect their responses to climate change. Invasive plant species also often have characteristics that facilitate rapid range shifts, such as low seed mass and short time to maturity (Hellmann et al., 2008). Lastly, invasive species are managed in a fundamentally different way than most native species, and this leads to virtually opposite sets of concerns under climate change (Hellmann et al., 2008).

Not all alien species establish and naturalize themselves to become "invasive" to the ecosystem into which that they are introduced. So care should be taken whenever considering which species are invasive and which are not. Likewise, native species may be invasive, particularly when the ecosystem is disturbed for reasons such as nutrient enrichment (eutrophication) of water bodies, altered flow regimes, changes as a result of alien water weeds (like for instance Water Hyacinth) (CABI, 2007; Sintayehu, 2007).

There is no distinct measurement for determining invasiveness. However, it is agreed that every species that has been removed from its natural environment have high propensity to become invasive. There are exacerbating factors to this. For instance species that are known for promiscuity and breed faster have more chance to invade than others. Some species may be highly adaptable in new environments and take advantage of ecological disturbances (Sintayehu, 2007). Generally, IAS, such as weeds, pests and diseases, are extremely adaptable to a changing climate. Invasive alien species also tend to have rapid dispersal characteristics, which allow them to shift ranges quickly in response to changing climatic conditions. As a result, these species could become more dominant in many areas under changing climate conditions (CABI, 2009).

However, CABI (2007) and Sintayehu (2007), pointed that certain species characters and circumstances are identified to be instrumental in predicting invasiveness by the following:

$>$ Knowledge that a certain species is invasive elsewhere in the world,

$>$ Widespread distribution and abundance in the native range,

$>$ High adaptability (tolerance) to a variety of environmental conditions,

$>$ Ability to grow and mature rapidly (reach reproductive age quickly),

$>$ High reproductive output (populations built quickly),

$>$ Ability to colonize from a single pregnant female,

$>$ Effective dispersal mechanisms, enabling rapid spread once established,

$>$ Tolerance of various types of soils for invasive plants,

$>$ Aggressive behaviour and competitive ability,

$>$ Association with humans,

$>$ Small size, making both detection and control difficult

The Interaction of Climate Change and Invasion

For several reasons it is useful to examine climate change responses of invasive species separately from those of native species. Climate change is likely to favours invasive species through decreased resistance of native communities to invasion, increased disturbance events such as fire, flood, storms and drought that favor traits of invasive species and more hospitable climates for invasive species to cross frontiers (Chai et al., 2014). Further, invasive plant traits generally predispose them to benefit from climate change; these include short generation time, good dispersal ability, broad environmental tolerance and rapid growth (Bradley et al., 2010). Because of its pervasiveness and potential effect on fundamental biological processes, climate change will interact with other existing stressors to affect the distribution, spread, abundance, and impact of invasive species (Chai et al., 2014).

Replacement of natives by invasive species will be one of the major impacts of climate change, but there will be others such as changing relationships between predators, pathogens and prey, changing fire regimes, and other climate harm to species already threatened by invasive species (CABI, 2009). The disturbance of ecosystems as caused by changing global environmental conditions will likely favour the propagation of invasive alien plant species. Because: firstly, alterations in climate will result in increasing variety in ecosystem conditions, which will increase the probability of invasive alien plants finding habitats suitable for their propagation, and secondly, invasive alien species tend to demonstrate greater adaptability to disturbance than native species, giving them a marked advantage in competition for resources within an ecosystem (Vilà, et al., 2010).

Climate change also will challenge the definition of invasive species because some taxa that were previously invasive may diminish in impact; other, previously noninvasive species, may become invasive; and many native species will shift their geographic distributions, moving into areas where they were previously absent (Hellmann et al., 2008). These are all reasons to specify carefully what is meant by an invasive species. Invasive species as those taxa that have been introduced recently and exert substantial negative impact on native biota, economic values, or human health (Sundaram et al., 2018). Therefore, we do not consider a native species that has expanded its range under climate change to be invasive unless it causes discernable damage (Hellmann 
et al., 2008).

Sintayehu (2007), Theoharides and Dukes (2007) and Sundaram et al. (2018) reviewed how climate change is likely to affect the four stages of the invasion 'pathway': (1) transport/introduction, (2) colonization, (3) establishment, and (4) landscape spread. A species must typically pass through a variety of environmental filters

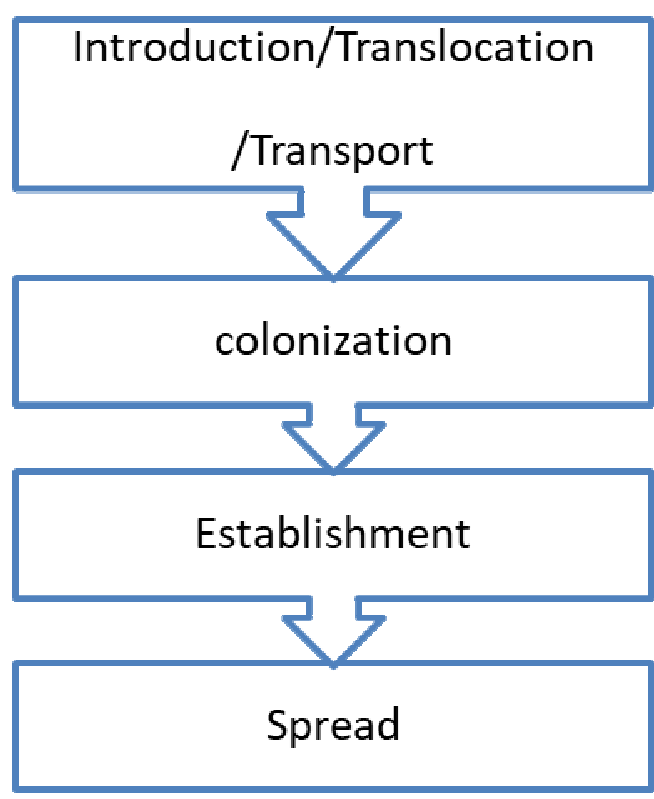

Figure 1 A. Stages/ process of the invasion pathway at each of these stages before it be-comes invasive (Fig $1 \mathrm{~A}$ and B) (Theoharides and Dukes, 2007; Hellmann et al., 2008). Climate change can potentially impact each of these stages in different ways (Sundaram et al., 2018).

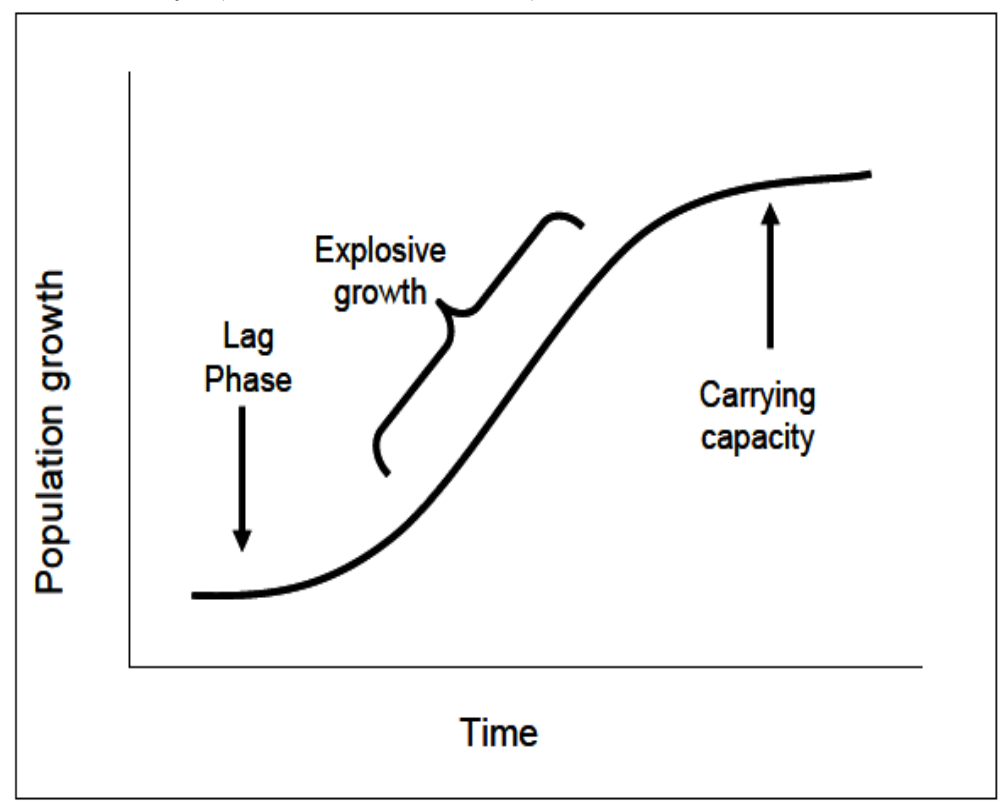

Figure1 B. The phase of an invasion (Adapted from Sintayehu (2007), Theoharides and Dukes (2007) and Sundaram et al. (2018))

Introduction (translocation, transportation) requires the intercontinental movement of species to an area outside its natural range, intentional or unintentional (Seebens et al. 2015; Sundaram et al., 2018). The reasons for intentional introduction may be their use as food, ornamental services or social or economic purposes (CABI, 2007; Sintayehu, 2007). Unintentional introduction has been recently exacerbated through the proliferation of global trade, increased and swifter modes of transportation in use and tourism. Unintentional introductions are relatively a huge threat because of their magnitude and "unplanned nature" (Shine, 2000; Sintayehu, 2007).

Once species have successfully been transported outside of their original environment, they are exposed to a different set of environmental conditions and biotic exposure. Success in adaptation to these new abiotic and biotic conditions enable them to settle into the second stage of the invasion process which is colonization (Sundaram et al., 2018). A fraction of species (10\%) that are transported are likely to successfully colonize a new area (Sundaram et al., 2018). Due to their high phenotypic plasticity, high capacity for hybridization, and broad environmental tolerance, the likelihood of successful colonization of species that have survived the transport stage will possibly increase with climate change (Theoharides and Dukes, 2007). Moreover, with climate change, species that are currently unsuccessful may find conditions changed to facilitate successful colonization. Because of their capacity for rapid reproduction, and their enhanced nutrient use efficiency, nonnative species that are lying in wait may find conditions that favour colonization, and may therefore progress further along the invasion pathway (Sundaram et al., 2018).

Once a species has successfully colonized an area, its capacity to develop self-sustaining and expanding populations determines its establishment, which is the third stage in the invasion pathway. The species must also persist and reproduce to form a self-sustaining population (also known as the "founder population"). This is the process commonly referred to as "establishment". The survivors must persist and reproduce until they establish a self-sustaining population. The next crucial phase in the invasiveness cycle is the explosion phase (Fig 1B), which is characterized by multiplication of the species in order to become sufficient for the invasion (Sintayehu, 2007). At this stage, small subpopulations of individuals may be linked through dispersal, and may come out as winners in ecosystems where they either face reduced competition from native species, or represent functional groups either absent, or present in low abundance, within the community (Melbourne et al., 2007), thereby 
giving colonizer species an edge over native species. At this stage, habitat heterogeneity and the availability of empty niche space also play a role in cementing establishment.

Climate change is likely to cause climatic range restrictions and expansions of native and non-native species. Qian and Ricklefs (2006) likened this scenario of simultaneous constriction and expansion of range as a zerosum game, where some non-native species that are habitat generalists are likely to benefit from range expansion, while those that are habitat specialists are likely to be negatively impacted by range constriction. However, in the long term, the shifting of climatic range restrictions is likely to tip the scales in favour of invasive species due to their broad environmental tolerances and high phenotypic plasticity (Theoharides and Dukes, 2007; Sundaram et al., 2018).

The final stage of the invasion pathway, landscape spread, is represented by invasive species forming a regional meta-community, where groups of populations are connected through long-distance dispersal (Melbourne et al., 2007). Within a heterogeneous landscape, populations of invasive species exist as interacting groups of species at different stages of colonisation and establishment (Sundaram et al., 2018). In certain cases, established populations will multiply rapidly and spread across the landscape. This is the explosion phase, and may only happen after a considerable lag phase (Fig 1B) (Sintayehu, 2007). Theoharides and Dukes (2007) posit landscape spread as incorporating 'ideal' conditions from all three previous stages in the invasion pathway: regional spread rates of invasive species are influenced by landscape heterogeneity, the size, distribution, and availability of suitable habitat for colonization and establishment, and population characteristics, growth rates, and dispersal ability of invasive species.

Therefore, the final stage of the invasion pathway is a culmination of biotic and abiotic factors that enable landscape spread. Leishman and Gallagher (2015) suggest that the responses of native and alien species to changes in carbon dioxide, temperature, and rainfall will be strongly species and context dependent, so that alien invaders will not consistently be favoured. However, climate change is likely to reduce resilience of vegetation assemblages resulting in increased colonisation probability, presenting a window of opportunity that invasive species are best placed to take advantage of_(Sundaram et al., 2018).

Similarly, Hellmann et al. (2008) pointed, on the basis of the invasion pathway (Fig. 1), there are 5 possible consequences of climate change for invasive species: (1) altered mechanisms of transport and introduction, (2) altered climatic constraints on invasive, species, (3) altered distribution of existing invasive species, (4) altered impact of existing invasive species, and (5) altered effectiveness of management strategies for invasive species. These consequences are not mutually exclusive because more than one outcome is likely, but they are comprehensive. The consequences focus on climatic change (i.e., temperature and precipitation), but the effects of elevated $\mathrm{CO}_{2}$ itself also can be incorporated into the 5 groupings (Hellmann et al., 2008).

Climate change can also lead to the establishment of new invasive species via 3 mechanisms. First, species currently unable to persist in a location because of climatic constraints may be increasingly able to survive and colonize that area (Hellmann et al., 2008). Second, arriving species that can tolerate the climate may have a greater chance of overcoming biotic constraints on their growth and establish persistent populations under climate change. Because climate change is expected to shift native species out of the conditions to which they are adapted, competitive resistance from native species may lessen (Byers, 2002). Third, established non-native species could become invasive if climate change increases their competitive ability or rate of spread. The "lag phase" in invasions, in which species that establish small seemingly non-invasive populations shortly after arrival and later become aggressively invasive, is well recognized (Hellmann et al., 2008).

\section{Impacts of Invasive Alien Species}

The impacts of IAS can be dramatic. The introduction of alien organisms into a new environment can have serious negative consequences for the environment and local biodiversity, for industries and users of natural resources, and also for the health and welfare of those associated with the affected systems. Invasive species are considered to be a part of global change, and act synergistically with climate change and other anthropogenic changes (Kuczynski et al., 2018). Impacts can be direct and indirect, the principal consequences can be ecological, economic and public health and society. While, this paper reviewed that these negative impacts of invasive alien species synergetic with climate change categorized into ecological and socio-economic strass of the world.

\section{Ecological and Biodiversity Stress}

Ecological impacts occur when the local biodiversity of the area and/or the ecological processes are altered by the invasive species. According to CABI (2005), IAS affect native biodiversity through a diversity of ecological processes, such as: Direct predation/herbivory; competition for resources, such as nesting sight, light or preferred food/nutrients; Habitat alteration; Spreading pathogens and parasites; Upsetting ecological balances and interactions, such as producing more attractive flowers for pollinators, or causing native prey populations to decrease to the point that they can no longer cope with natural predation rates, even if the IAS 
is removed and synergies with other IAS, such as degrading the environment so that further invasions are facilitated

IAS have invaded and affected native biota in virtually every ecosystem type on Earth. They have contributed too many hundreds of extinctions, under island conditions, freshwater ecosystems (Shiferaw et al., 2018). All ecosystems can be invaded potentially; some appear more vulnerable than others. Evolutionarily and geographically isolated ecosystems, notably oceanic islands are particularly vulnerable. Most probably habitats such as urban-industrial areas, habitats suffering from periodic disturbance, harbors, lagoons, estuaries and the fringes of water bodies are under threats of IAPs. Moreover, population pressure, over-stocking, overgrazing and deforestation have facilitated the disturbance of the natural ecosystem and enhanced the effect of weed invasion by threatening biodiversity of the country (Lowe et al., 2000).

Invasion by alien species and their subsequent negative impacts on biodiversity and ecosystem services namely on provisioning of resources, agriculture production, economy, and human health are critical components of human-mediated global environmental changes (Pyšek and Richardson, 2010; Matthews et al., 2017). Biological invasions are also considered to be one of the major drivers of biodiversity loss and species extinctions (McGeoch et al., 2010; Bellard et al., 2016).

Introduced species that become invasive can have a massive impact on the ecosystem they invade, causing severe damage to biodiversity and human economy. As such, biological invasions are currently considered a component of global change, and along with habitat destruction and global warming, they are considered one of the greatest threats to biodiversity worldwide (Mooney and Cleland, 2001; MA, 2005; Vila et al., 2010).

They are pausing threats to ecosystems of the earth, and the services that they provide to humanity are under risk. IAS have induce impacts on native species directly competing for resource such as: food and breeding sites indirectly by altering habitat and modify hydrology, nutrient cycling and other ecosystem processes. Their impacts are on native biodiversity in ecosystems like agricultural and range lands, national parks, water ways, lakes, rivers, power dams, road sides and urban green spaces with huge economical as well as social consequences. These dramatically change the ecosystem both positively and negatively (Shiferaw et al., 2018).

A large proportion of globally and locally threatened species and ecosystems are at risk from invasive alien species. Habitat loss remains the primary threat to most species, but the impact of invasive alien species is an additional significant threat. The impacts on oceanic islands are serious, with a majority of all extinctions of mammals, birds, amphibians, reptiles, land crabs, land snails and insects being directly or indirectly the result of invasive alien species (IPBES, 2015).

For many countries, invasive alien species are seen as a more serious threat than climate change. Such species have been responsible for the extinction of native plants and animals, degradation of rare and threatened ecosystems and ecological communities, crop failure and declining agricultural productivity, loss of cultivar and animal breed diversity and damage to property, infrastructure, native fisheries, tourism and outdoor recreation (IPBES, 2015). This invasive mussel may thus have the 'power' to alter the structure and function of entire ecosystems (Scalera et al., 2012; Genovesi et al., 2015). Climate change is also expected to substantially alter biodiversity, causing changes in phenology, genetic composition, and species ranges, and affecting species interactions and ecosystem processes (Walther et al. 2002; Root et al. 2003). Climate change is likely to bring about a number of changes in the structure and functioning of ecosystems. Terrestrial and aquatic ecosystem properties that are likely to be affected by increasing atmospheric $\mathrm{CO} 2$ and global temperatures include changes in ecosystem productivity, biogeochemical cycles and carbon dynamics, altered disturbance regimes, and altered food chains and food webs (Wrona et al., 2006; Grimm et al., 2013).

Invasive species are a problem because they affect ecosystem properties, ecosystem processes, and community structure (Perrings et al., 2000; Levine et al., 2003). The total impact of an invasive species on a community, ecosystem, or resource can be defined as the product of 3 terms: the size of the range occupied by the invasive species (its spatial extent), its average abundance within that range, and its per capita (or per-unit biomass) impact (Hellmann et al., 2008). The significance of this impact on a target native species or resource depends on the size of the native population or scarcity of native resources, factors that may be affected by climate change (Fig. 2). The absolute impact describes the actual change in populations, processes, or ecosystem services caused by the invasive species. The relative impact scales the importance of any absolute impact and can be expressed as a unit less proportion. More complex economic models should be used to accurately estimate the value of impacts (e.g., Zavaleta 2000; Hellmann et al., 2008). Despite evidence that impacts from invasive species will change, however, there are few good predictions of which invasive species will have greater effects under climate change (Hellmann et al., 2008). 


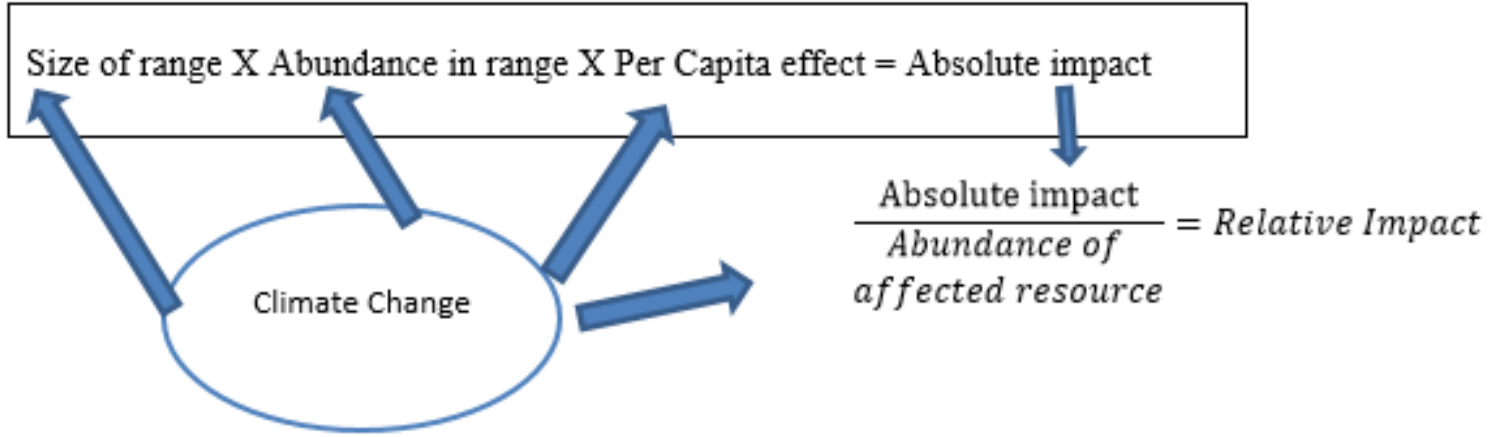

Figure 2. Conceptual diagram of mechanisms through which climate change can affect the ecological and economic impacts of invasive species (Adapted from Hellmann et al., 2008).

Generally, ecological impacts of IAS may include: Displacing native species, which causes changes in the ecosystem functioning, Causing extinctions, which may have "cascade" effects and cause further extinctions, Degrading ecosystem services (such as reducing river runoff volumes or water quality or destroying fisheries), Altering environmental conditions such as increasing erosion or changing natural fire regimes, Disturbing ecological processes and thereby facilitating invasion by other alien species and Altering of the food web and nutrient cycles (CABI, 2005)

\section{Socio-economic Stress}

A wide range of human activities are changing environments around the world, with deleterious effects on the species inhabiting these environments. Examples of these activities include agriculture and aquaculture, transporting non-native species carbon emissions into the atmosphere leading to climate change, biological resource use, pollution, and residential and commercial development. Species declines and extinctions are rarely associated with single driving processes (Bellard et al., 2016), and so it is possible that in many cases, native species declines and non- native species increases are coincidental, arising from simultaneous responses of native and non-native species to other anthropogenic disturbances

The economic consequences of biological invasions are also impressive. They also have a significant impact on economies: worldwide, for example, it has been estimated that the cost of damage from such species in 2001 exceeded \$1.4 trillion, amounting to 5 per cent of the global economy. The use of pesticides to control invasive alien species is also a major cause of the loss of biodiversity and represents a threat to human health. Similarly, invasive alien species may introduce pathogens leading to signficant public and agricultural health burden and associated disease treatment and control cost. (Intergovernmental Science-Policy Platform on Biodiversity and). In Europe alone it is estimated that the overall losses due to this threat are above 12 billion euro/year (Kettunen et al., 2009). IAS can also have severe impacts on human health. Infectious disease agents may themselves be IAS or may be introduced by IAS vectors (e.g. introduced mosquitoes carrying malaria, West Nile Virus). Diseases can affect the movement of people and limit tourists to an area. Besides diseases, other IAS are dangerous to humans (CABI, 2005).

Moreover, IAS may cause major economic losses and social impact to society, whether in the form of direct economic impacts or indirect (secondary economic impacts) (CABI, 2005). Direct costs economic impacts may include:

$\checkmark$ Direct loss of crops to introduced crop pests.

$\checkmark$ Spoiling of produce, rendering products unsuitable for consumption,

$\checkmark$ Loss of export earnings due to prohibitions on exporting products infected by IAS,

$\checkmark$ Reductions in agricultural production due to displacement of pasture by unpalatable grasses and woody species, and/or through habitat/environmental changes caused by the invading species

$\checkmark$ Impacts on fisheries and aquaculture

$\checkmark$ Secondary economic impacts from human health issues associated with introduced pathogens and toxic species, including increased monitoring, testing, diagnostic and treatment costs, and loss of social productivity due to illness and death in affected people

$\checkmark$ Loss of tourism revenues due to disease epidemics

$\checkmark$ Costs of producing and using chemicals and machines to deal with IAS

While indirect socio-economic IAS costs includes:

$\checkmark$ Degradation of ecosystem services, such as reduced water supplies from alien trees growing in catchments and along rivers, or siltation of dams and rivers due to increased soil erosion

$\checkmark$ Lost human productivity due to time and resources allocated to dealing with IAS, such as clearing weeds or spraying pesticides 
$\checkmark$ Damage to infrastructure due to ecosystem changes, such as increased intensity and/or frequency of fires, floods or landslides

$\checkmark \quad$ The costs of responding to the problem, including research and development, monitoring, education, communication, regulation, compliance, management, mitigation and control costs and restoration activities

\section{Conclusion and Farther Recommendations}

The greatest impacts of climate change on invasive species may arise from changes in the frequency and intensity of extreme climatic events that disturb ecosystems, making them vulnerable to invasions, thus providing exceptional opportunities for dispersal and growth of invasive species. Climate change may well provide additional triggers, by creating disturbances within the ecosystem that quiescent IAS can exploit. IAS may rapidly exploit the niches generated by climatic disturbance and the ecological consequences of climatic disturbance to ecosystems. Therefore, climate change and IAS will interact synergistically, greatly threatening food security, ecology, biodiversity, and human wellbeing. Consequently, imperative that prevention measures consider future interactions and synergies where these may increasingly exacerbate the IAS problem. IAS are drivers of climate change, but climate change can greatly facilitate the spread of these species and exacerbate the resultant degradation of biodiversity.

The threat of IAS to biodiversity, economies and human health is real and need to be taken seriously by the global community. Everybody has a part to play in the fight against IAS whether at the individual, community, national or international level. The future of management of invasive species will involve new tools developed from research that integrates invasion and climate-change biology. Increased monitoring and more interagency and interstate coordination will also be necessary. Recognition of these facts, and of the impacts caused by invasive species, has led to the development of a variety of strategies for their prevention and control. The following recommendations are suggested to prevent, control the already invaded ecosystems:

$\checkmark$ Close monitoring and management of all natural and agro-ecosystems from disturbances to reduce the arrival and colonization of IAS.

$\checkmark$ Secure quarantine measures needs to be introduced in boarder areas where tourism, trade, travels agents are flowing.

$\checkmark$ Countries with IAS countries share information and working relationships in order to control the transfer of IAS from one to another.

$\checkmark$ Create awareness for stakeholders about IAS and impact on environment.

$\checkmark$ Governmental and non-governmental institutions should use better efforts to control IAS

$\checkmark$ IAS should be recognized as a component of climate change and as such appropriate research strategies, funding mechanisms, policy development and implementation need to be developed.

$\checkmark$ Efforts to prevent, control, or mitigate the environmental impacts of these species soak up substantial financial and social resources from conservation organizations and concerned governments.

$\checkmark$ Sustainable and multidisciplinary approach studies regarding history, properties of the invasiveness of the species and their impacts in relation to ecological impacts on ecosystems and socioeconomic consequences have to be conducted.

\section{References}

Bellard, C., Cassey, P., Blackburn, T.M., (2016). Alien species as a driver of recent extinctions. Biol. Lett.-U.K. 12 (2), 20150623.

Bellard, C., Thuiller, W., Leroy, B., Genovesi, P., Bakkenes, M., Courchamp, F., (2013). Will climate change promote future invasions? Global Change Biol. 19 (12), 3740-3748.

Blackburn TM, Cassey P, Duncan RP et al (2004). Avian extinction and mammalian introductions on oceanic islands. Science 305:1955-1958

Boria, R.A., Olson, L.E., Goodman, S.M., Anderson, R.P., (2014). Spatial filtering to reduce sampling bias can improve the performance of ecological niche models. Ecol. Model. 275, 73-77.

Bradley, B.A., Oppenheimer, M., Wilcove, D.S., (2009). Climate change and plant invasions: restoration opportunities ahead. Global Change Biol. 15 (6), 1511-1521.

Byers, J. E. (2002). Impact of non-indigenous species on natives enhanced by anthropogenic alteration of selection regimes. Oikos97:449-458.

CABI (2009). Climate change and Invasive alien species CABI Position Paper July 2009.

CABl (2005). Module 1: Introduction to Invasive Alien Species.

CABl-Africa. (2007). Drafting Legal and Institutional Frameworks for the Management of Invasive Alien Species. (Trai ning Document), CABI-Africa, Nairobi, Kenya. CBD.

Chai, S., Nixon, A., Zhang, J. and Nielsen, S. (2014). Predicting invasive plant response to climate change: Prioritization and mapping of new potential threats to Alberta's biodiversity. Prepared for the Biodiversity 
Management and Climate Change Adaptation Project March, 2014

Crossman, N.D., Bryan, B.A., Cooke, D.A., 2011. An invasive plant and climate change threat index for weed risk management: integrating habitat distribution pattern and dispersal process. Ecol. Indic. 11 (1), 183-198.

Genovesi, P., Carnevali, L. and Scalera, R, (2015). The impact of invasive alien species on native threatened species in Europe. ISPRAMISSG, Rome. Technical report for the European Commission. Pp.18.

Grimm, N.B., F.S. Chapin, B. Bierwagen, P. Gonzalez, P.M. Groffman, Y. Luo, F. Melton, et al. (2013). The impacts of climate change on ecosystem structure and function. Frontiers in Ecology and the Environment 11(9): 474-482.

Gritti, E. S., B. Smith, and M. T. Sykes. (2006). Vulnerability of Mediterranean Basin ecosystems to climate change and invasion by exotic plant species. Journal of Biogeography33:145-157.

Hellmann, J.J., Byers, J.E., Bierwagen, B.G., Dukes, J.S., (2008). Five potential consequences of climate change for invasive species. Conserv. Biol. 22 (3), 534-543.

Kuczynski, L., P. Legendre, and G. Grenouillet. (2018). Concomitant impacts of climate change, fragmentation and non-native species have led to reorganization of fish communities since the 1980s. Global Ecology and Biogeography 27(2): 213-222.

Leishman, M.R., and R. V Gallagher. (2015). Will there be a shift to alien-dominated vegetation assemblages under climate change?. Diversity and Distributions 21(7): 848-852.

Levine, J.M., M. Vila, C.M. D’Antonio, J.S. Dukes, K. Grigulis, and S. Lavorel. (2003). Mechanisms underlying the impacts of exotic plant invasions. Proceedings of the Royal Society of London Series Biological Sciences 270:775-781.

Lowe S, Browne M, Boudjelas S, De Poorter M. 100 of the world's worst invasive alien species a selection from the global, invasive species database. ISSG. 2000;6:1-11.

Macdougall, A.S., and R. Turkington. (2005). Are invasive species the drivers or passengers of change in degraded ecosystems. Ecology 86(1): 42-55

Matthews, J., Velde, G., Collas, F.P.L., De Hoop, L., Koopman, K.R., Hendriks, A.J., Leuven, R.S.E.W., (2017). Inconsistencies in the risk classification of alien species and implications for risk assessment in the European Union. Ecosphere 8 (6), e01832.

McGeoch, M.A., Butchart, S.H., Spear, D., Marais, E., Kleynhans, E.J., Symes, A., Chanson, J., Hoffmann, M., (2010). Global indicators of biological invasion: species numbers, biodiversity impact and policy responses. Divers. Distrib. 16 (1), 95-108.

McNeely, J.A. (2001). Invasive species: a costly catastrophe for native biodiversity. Land Use and Water Resources Research, 1(2): 1-10.

Melbourne, B.A., H. V Cornell, K.F. Davies, C.J. Dugaw, S. Elmendorf, A.L. Freestone, R.J. Hall, et al. (2007). Invasion in a heterogeneous world: resistance, coexistence or hostile takeover. Ecology Letters 10(1): 77-94.

Mooney HA, Cleland EE (2001) The evolutionary impact of invasive species. PNAS 10: 5446-5451.

Paini, D.R., Sheppard, A.W., Cook, D.C., De Barro, P.J., Worner, S.P., Thomas, M.B., (2016). Global threat to agriculture from invasive species. P. Natl. Acad. Sci. U.S.A. 113 (27), 7575-7579.

Pejchar, L., and H.A. Mooney. (2009). Invasive species, ecosystem services and human well-being. Trends in Ecology and Evolution 24(9): 497-504.

Perrings, C., M.H. Williamson, and S. Dalmazzone. (2000). The Economics of Biological Invasions. Edward Elgar, Cheltenham, United Kingdom.

Pimentel, D., Zuniga, R., Morrison, D., (2005). Update on the environmental and economic costs associated with alien-invasive species in the United States. Ecol. Econ. 52 (3), 273-288.

Preisser EL, Lodge AL, Orwig DA, E1kinton JS (2008). Range expansion and population dynamics of cooccuring invasive herbivores. BioI. Invasions 10: 201-213.

Pyšek, P., Richardson, D.M., (2010). Invasive species, environmental change and management, and health. Annu. Rev. Environ. Resour. 35, 25-55

Qian, H., and R. E. Ricklefs. (2006). The role of exotic species in homogenizing the North American flora. Ecology Letters9:1293-1298.

Root, T. L., J. T. Price, K. R. Hall, S. H. Schneider, C. Rosenzweig, and J. A. Pounds. (2003). Fingerprints of global warming on animals and plants. Nature 421:57-60.

Seebens, H., Blackburn, T.M., Dyer, E.E., Genovesi, P., Hulme, P.E., Jeschke, J.M., Pagad, S., Pysek, P., Winter, M., Arianoutsou, M., Bacher, S., Blasius, B., Brundu, G., Capinha, C., Celesti-Grapow, L., Dawson, W., Dullinger, S., Fuentes, N., Jager, H., Kartesz, J., Kenis, M., Kreft, H., Kuhn, I., Lenzner, B., Liebhold, A., Mosena, A., Moser,D., Nishino, M., Pearman, D., Pergl, J., Rabitsch, W., Rojas-Sandoval, J., Roques, A., Rorke, S., Rossinelli, S., Roy, H.E., Scalera, R., Schindler, S., Stajerova, K., TokarskaGuzik, B., van Kleunen, M., Walker, K., Weigelt, P., Yamanaka, T., Essl, F., (2017). No saturation in the accumulation of alien species worldwide. Nat. Commun. 8, 14435. https://doi.org/10.1038/ncomms14435.

Seebens, H., Essl, F., Dawson, W., Fuentes, N., Moser, D., Pergl, J., Pyšek,P., vanKleunen, M., Weber, E., 
Winter, M., Blasius, B., (2015). Global trade will accelerate plant invasions in emerging economies under climate change. Global Change Biol. 21 (11), 4128-4140.

Senayit, R., Agajie T., Taye T., Adefires W., and Getu E. (2004). Invasive Alien Plant Conlrol and Prevenlion in Elhiopia. Pilol Surveys and Control Baseline Condilions. Report submilled to EARO, Ethiopia and CA BI under the PDF B phase of the UNEP GEF Project - Removing Barriers to Invasive Planl Managemenl in Africa. EARO, Addis Ababa, Ethiopia.

Shiferaw W, Demissew S, Bekele T. Invasive alien plant species in Ethiopia: ecological impacts on biodiversity a review paper. Int J Mol Biol Open Access. 2018;3(4):169-176. DOI: 10.15406/ijmboa.2018.03.00072

Shine, c., N. Williams and L. Gund1ing, (2000). A Guide to Designing Legal and Institutional Frameworks on Alien Invasive Species. IUCN, Gland, Switzerland Cambridge and Bonn. XVI + 138 pp.

Simberloff, D., Martin, J.L., Genovesi, P., Maris, V., Wardle, D.A., Aronson, J., Courchamp, F., Galil, B., García-Berthou, E., Pascal, M., Pyšek, P., 2013. Impacts of biological invasions: what's what and the way forward. Trends Ecol. Evol. 28 (1), 58-66.

Sintayehu W. (2007). A Legislative Approach to the Management of Invasive Alien Species in Ethiopia: the case of Prosopis julijlora in Gewane Woreda. Thesis for the Degree of Master of Arts in Environment and Development, Addis Ababa University, Ethiopia.

Smith L, Nina Hewitt, Nicole Klenk, Dawn R. Bazely, Norman Yan, Stepan Wood, Irene Henriques, James I. MacLellan, and Carla Lipsig-Mummé (2012). Effects of climate change on the distribution of invasive alien species in Canada: a knowledge synthesis of range change projections in a warming world. Environ. Rev. $20: 1-16$

Steffen, W., K. Richardson, J. Rockström, S.E. Cornell, I. Fetzer, E.M. Bennett, R. Biggs, et al. (2015). Planetary boundaries: guiding human development on a changing planet. Science 347(6223): 1259855

Sundaram, B., Ramaswami, G., Paul, M. and Hiremath, A.J. (2018). Synergistic Impacts of Invasive Alien Species and Climate Change: Implications for Biodiversity Conservation. https://www.researchgate.net/publication/331197817

Thapa S, Chitale V, Rijal SJ, Bisht N, Shrestha BB (2018). Understanding the dynamics in distribution of invasive alien plant species under predicted climate change in Western Himalaya. PLoS ONE 13(4): $\mathrm{e} 0195752$.

Theoharides, K. A., and J. S. Dukes. (2007). Plant invasion pattern and process: factors affecting plant invasion at four spatio-temporal stages.New Phytologist176:256-273.

Tilman, D., M. Clark, D.R. Williams, K. Kimmel, S. Polasky, and C. Packer. (2017). Future threats to biodiversity and pathways to their prevention. Nature 546(7656): 73-81.

Vié, J.-C., Hilton-Taylor, C. and Stuart, S.N. (eds.) (2009). Wildlife in a Changing World - An Analysis of the 2008 IUCN Red List of Threatened Species Gland, Switzerland: IUCN. 180 pp 6 Pimentel D et al. 2001. Economic and environmental threats of alien plant, animal, and microbe invasions. Agric. Ecos. Env, 84:120

Vilà M, Basnou C, Pyšek P, Josefsson M, Genovesi P, Gollasch S, Nentwig W, Olenin S, Roques A, Roy D, Hulme PE (2010). How well do we understand the impacts of alien species on ecosystem services. A panEuropean, cross-taxa assessment. Frontiers in Ecology and the Environment 8(3): 135-144.

Walther,G.-R.,E.Post,P.Convey,A.Menzel,C.Parmesan,T.J.C. Beebee, J.-M. Fromentin, O. Hoegh-Guldberg, and F. Bairlein. (2002). Ecological responses to recent climate change. Nature 416:389- 395.

With, K.A., (2002). The landscape ecology of invasive spread. Conserv. Biol. 16 (5),1192-1203.

Wrona, F.J., T.D. Prowse, J.D. Reist, J.E. Hobbie, L.M.J. Lévesque, and W.F. Vincent. 2006. Climate change effects on aquatic biota, ecosystem structure and function. Ambio 35(7): 359-369.

Zavaleta, E. (2000). The economic value of controlling an invasive shrub. Ambio29:462-467.

Zelalem Getachew, (2007). Spalial Variation in Range Dynamics in Relation to Prosopis juliflora Invasion along River Awash, Gewane Dislrict, North East Elhiopia, M.Sc Thesis, Haramaya University. 